\title{
Flujo de materia en un manglar de la costa de Chiapas, México
}

\author{
D. Edith Orihuela Belmonte ${ }^{1}$ \\ Cristian Tovilla Hernández ${ }^{2}$ \\ Henricus Franciscus M. Vester ${ }^{3}$ \\ Teresa Álvarez Legorreta ${ }^{3}$
}

\begin{abstract}
RESUMEN
La importancia de los sistemas de manglar como fuente de ingreso económico para las comunidades humanas reside en la función que desempeñan como refugio y hábitat para una gran diversidad de organismos acuáticos y terrestres. Con el objetivo de contribuir a un plan de manejo en el sistema Lagunar Pampa Murillo se construyó un modelo del flujo de materia dentro y hacia afuera del manglar con base en estudios de producción de hojarasca, herbivoría, degradación de hojas y exportación de detritus hacia la zona marina. De enero a octubre se realizaron los estudios en cuatro especies de mangle: Rhizophora mangle, Laguncularia racemosa, Avicennia germinans y Conocarpus erectus. En este sistema la producción diaria de hojarasca fue $3,9 \mathrm{~g} / \mathrm{m}^{2}$, lo que equivale a $7,9 \mathrm{t} \mathrm{C} / \mathrm{ha}$, el porcentaje de consumo en peso sobre las hojas realizado por los herbívoros fue de $13,6 \%$ en $A$. germinans, $12,5 \%$ en $L$. racemosa, $9,8 \%$ en $R$. mangle y $5,7 \%$ C. erectus. La especie más resistente a la degradación fue $C$. erectus, que en 210 días perdió menos de $50 \%$ de la materia orgánica inicial contenida en las hojas; mientras que $A$. germinans en el mismo tiempo perdió $87,6 \%$ de la materia orgánica. De la productividad del bosque, el sistema exporta 0,5 t de peso seco/hora de detritus en el mes de mayo; mientras en octubre se eleva a 1,5 t/h (peso seco), para un total de 4 822,2 t C/año que salen del sistema con $54,5 \%$ de materia orgánica, constituyendo un subsidio alimenticio para la zona marina adyacente.
\end{abstract}

PALABRAS CLAVE:

Degradación, exportación de detritus, herbivoría, productividad.

\begin{abstract}
The importance of mangrove systems as a source of income for coastal communities resides in their function as refuges and habitats for a great diversity of aquatic and terrestrial organisms. With the objective of developing a management plan for the Pampa-Murillo lagoon system, a model of the flow of matter inside and emanating from the mangrove was designed. The model was based on records of leaf litter production, herbivory, decomposition of fallen leaves and detritus movement towards the marine zone. Data was gathered from January to October in four types of mangrove forest where Rhizophora mangle, Laguncularia racemosa, Avicennia germinans and Conocarpus erectus species were present. In this system the daily production of leaf litter was $3,9 \mathrm{~g} / \mathrm{m}^{2}$, equivalent to $7,9 \mathrm{t} \mathrm{C} / \mathrm{ha}$. The major leaf consumption by herbivores was in $A$. germinans with $13,6 \%$, followed of $L$. racemosa $(12,5 \%)$, R. mangle $(9,8 \%)$, being the lowest in $C$. erectus $(5,7 \%)$. The most resistant species to degradation was $C$. erectus which lost lower than $50 \%$ of the initial organic matter content of its leaves over a period of 210 days. In contrast, $A$. germinans degraded most quickly retaining only $12,4 \%$ of initial organic matter content after the same period. Of the organic matter produced by the forests, the mangrove system exports the least amount of detritus in May (0,5 t dry weigth/h), whereas detritus movement rises to $1,5 \mathrm{t} / \mathrm{h}$ (dry weight) in October. This represents the equivalent of approximately 4 $822,2 \mathrm{t} \mathrm{C} /$ year, of which $54,5 \%$ is organic matter. This material constitutes an important nutritional input into the adjacent marine zone.
\end{abstract}

KEY WORDS:

Decomposition, export of detritus, herbivory, leaf litter production.

2 El Colegio de la Frontera Sur Unidad Tapachula. Laboratorio de ecología de manglares. Carretera Antiguo Aeropuerto km. 2.5 Tapachula 30700 Chiapas, México. c.e.: ctovilla@tap-ecosur.edu.mx.

3 Ecosur Chetumal Zona Industrial No. 2 Carretera Chetumal-Bacalar 77000 Quintana Roo, México. c.e.: hvester@ecosur-qroo.mx, teral@ecosur-qroo.mx. 


\section{INTRODUCCIÓN}

Los manglares ocupan extensiones considerables a lo largo de la zona costera de las regiones tropicales. En México, cubren un área aproximada de 550000 hectáreas, tanto en el Golfo de México, el Mar Caribe y el Océano Pacífico (Lacerda et al., 1993). La importancia de los sistemas de manglar como fuente de ingreso económico para las comunidades humanas reside en la función que desempeña como refugio y hábitat para una gran diversidad de organismos acuáticos y terrestres que en su gran mayoría dependen de lo que el manglar produce.

El sistema de manglar funciona a partir de los subsidios de materia (nutrientes, sedimentos, materia orgánica, agua dulce y salobre) y energía recibida (luz, temperatura, oleaje, mareas y huracanes). Estos elementos permiten al aparato fotosintético producir cierta cantidad de biomasa que se expresa en términos de materia orgánica (producción primaria); la cual es variable debido a diferentes factores como latitud, estacionalidad y precipitación. Esta producción en la mayoría de los casos ha sido cuantificada en los manglares a través de la caída de hojarasca (Golley et al., 1962; Rico-Gray y Lot-Helgueras, 1983; Steinkey y Charles, 1983; 1984).

Todas las plantas experimentan cierto grado de forrajeo sobre su estructura, lo cual implica un consumo por diferentes organismos sobre raíces, tallos, flores, propágulos y hojas; este consumo se conoce como herbivoría (Onuf et al., 1977). De manera general, en los manglares la herbivoría es baja y sólo la realizan organismos como insectos y crustáceos, debido a que estos vegetales poseen gran cantidad de sustancias de olor y sabor desagradables como los taninos (Southwell y Boltman, 1971; Beever et al., 1979).
La materia orgánica producida en el manglar es transformada a través del proceso de degradación. La velocidad con que se realiza este proceso es variable y depende del ambiente de degradación, contenido de proteína, celulosa, lignina y de la composición química del tejido en descomposición, el cual ofrecerá mayor o menor resistencia a los microorganismos (Heald, 1969; Ulken, 1984; Bremer, 1995). La hojarasca cae constantemente al piso, es removida cuando se deposita en sitios inundados donde se inicia el proceso de degradación, el cual puede ser lento en $R$. mangle o rápido en $A$. germinans (Tovilla, 1998).

Bajo la influencia de la marea, la hojarasca se redistribuye constantemente. Una buena parte de esta materia se queda dentro del sistema y es reciclada al interior de los bosques; mientras que otra parte es exportada hacia la zona marina como detritus. De acuerdo con el contenido de materia orgánica presente en el detritus, éste representa un subsidio para muchas cadenas alimenticias, dentro de las cuales destacan especies de interés comercial como el camarón, tanto en los estuarios como en el mar (Flores-Verdugo et al., 1987; Wolanski, 1995; Lee, 1995).

Los bosques de mangle en la costa del Pacífico del Estado de Chiapas, son importantes por su extensión (82 789 ha), estructura y funciones que desempeñan, así como por servir de hábitat para muchos organismos, entre las cuales destacan las comunidades de crustáceos, moluscos, anélidos, peces, anfibios, reptiles, aves y mamíferos, que existen dentro de estos ecosistemas (Tovilla, 1998).

\section{OBJETIVO}

Contribuir a un plan de manejo del sistema Lagunar Pampa Murillo por 
medio de la construcción de un modelo del flujo de materia dentro y hacia afuera del manglar con base en la cuantificación de producción de hojarasca, herbivoría, degradación de hojarasca y exportación de detritus hacia la zona marina.

\section{METODOLOGÍA}

El área de estudio se encuentra ubicada en el Sistema Lagunar de Pampa Murillo (Fig. 1), Municipio de Tapachula, a los $14^{\circ} 39^{\prime} 09^{\prime \prime}$ Latitud N y $92^{\circ} 20^{\prime} 07^{\prime \prime}$ Longitud W; con una extensión aproximada de 3104 hectáreas, de las cuales alrededor de 2139 hectáreas, están cubiertas por manglares, selva baja inundable, tulares y vegetación halófita. El resto del sistema está constituido por cuerpos de agua permanentes y estacionales, sobre los cuales se realiza una importante actividad pesquera de tipo artesanal (SERNyP, 1998).

Producción de hojarasca: la cuantificación de la caída de hojarasca se realizó mensualmente a partir de enero y hasta octubre de 2001 en ocho sitios o estaciones del sistema. En cada sitio se colocaron 10 trampas de $0,5 \mathrm{~m} \times 0,5 \mathrm{~m}$, construidas con malla de nylon de $1 \mathrm{~mm} \times 1$ $\mathrm{mm}$, distribuidas en una superficie de 2 $500 \mathrm{~m}^{2}$; se obtuvieron los parámetros: temperatura $\left({ }^{\circ} \mathrm{C}\right)$, salinidad intersticial (S $\%$ ) y nivel de inundación del suelo (cm). El material colectado se secó durante 72 horas a $60^{\circ} \mathrm{C}$, separando las fracciones que constituyen la hojarasca y obteniendo el peso de cada fracción según los criterios de Cintrón y Schaeffer-Novelli (1981). Los resultados se expresan como gramos de peso seco/m²/tiempo (día/mes/año) y se transformaron a gramos de carbono, de acuerdo con el factor de conversión para manglares de Brown y Lugo (1981): $1 \mathrm{~g}$ de materia orgánica $=1 / 1,8 \mathrm{~g} \mathrm{C}$.

Herbivoría sobre las hojas del manglar: se estimó como el consumo realizado por los organismos sobre las hojas de dos ramas en la parte superior e inferior de la copa de 10 árboles marcados al azar en $R$. mangle, $L$. racemosa, $A$. germinans y $C$. erectus. En cada rama se tomaron al azar seis hojas, para un total de 12 hojas por árbol, para un tamaño de muestra de 120 hojas mes $^{-1}$ por especie de mangle, es decir 480 hojas $\mathrm{mes}^{-1}$, con dos repeticiones. En el laboratorio se pesó cada hoja. Para la cuantificación del consumo se utilizó un medidor de área foliar Hewlett Packard RL-83055, con el cual se determinó el área de la hoja consumida con una aproximación de 0,1 mm. La fracción consumida se expresó como el porcentaje del peso total de las hojas/mes. Estas determinaciones se realizaron siguiendo los criterios establecidos por Beever et al. (1979) y Cintrón y Schaeffer-Novelli (1981). Se realizaron capturas mensuales de los organismos que se encontraron pastoreando sobre las hojas, durante el día y en las primeras horas de la noche. En el caso de las orugas de lepidópteros se llevaron al laboratorio donde se desarrollaron hasta el estado adulto para su identificación.

Velocidad de degradación y contenido de materia orgánica: se pusieron a degradar 180 bolsas, cada una con $30 \mathrm{~g}$ de hoja por especie de mangle, para un total de 1440 bolsas, con dos repeticiones simultáneas. Las bolsas se colocaron a un metro de profundidad amarradas a las raíces del mangle, en un canal de marea (Heald, 1969). Cada 14 días se retiraban tres bolsas con sus respectivas replicas por especie. En el laboratorio se separaba al chorro de agua el material adherido al exterior de la bolsa, secándose durante 90 horas a 60 ${ }^{\circ} \mathrm{C}$, para obtener el peso seco total de la muestra. Para determinar el porcentaje de materia orgánica, se incineró un gramo de muestra durante una hora a $550^{\circ} \mathrm{C}$. El experimento concluyó cuando 
en las bolsas de degradación el peso del material restante era menor a $5 \%$ (Heald, 1969).

Materia orgánica exportada por el manglar: en el canal que comunica el sistema lagunar con el mar, cada mes, durante la marea baja, se colocó durante 5,5 horas una red cónica de $1 \mathrm{~m}$ de diámetro de boca $\times 2,5 \mathrm{~m}$ de largo, con malla de $1 \mathrm{~mm} \times 1 \mathrm{~mm}$. Por fuera de esta red se colocó otra de $500 \mathrm{~m}$. Todo el sistema estaba sujeto a un marco de metal, el cual se mantuvo amarrado a dos postes a la mitad del canal a $90 \mathrm{~cm}$ bajo la superficie. En la boca de la red se fijó un flujómetro para calcular el volumen de agua filtrado durante el experimento. Se calculó el flujo de agua que salía por el canal, para estimar la cantidad de detritus exportado por $\mathrm{m}^{3}$ mes $^{-1}$ de acuerdo a lo descrito por Baldor (1981). Al finalizar la marea baja, se sacaron las redes, colectando el material en bolsas de plástico. De este material se obtuvo el peso fresco y seco, así como el porcentaje de materia orgánica (Heald, 1969).

\section{RESULTADOS}

Producción de hojarasca:en el sistema lagunar Pampa Murillo existen dos tipos de bosques de mangle de acuerdo con la clasificación de Lugo y Snedaker (1974): manglar de borde y manglar de cuenca. De las ocho estaciones con trampas para hojarasca, cuatro corresponden a bosques de borde $(1,2,3$ y 5$)$; y las restantes son de cuenca $(4,6,7)$. La estación 8 es un rodal periférico en el límite de la cuenca. La producción total presentó un promedio en los ocho sitios de 13,7 t/ha/año equivalentes a 7,59 t/ha/año de carbono (C).

Bosques de borde: en las estaciones 1, 3 y 5 existen tres bosques puros de $R$. mangle, mientras que en la estación 2 se encuentra un bosque mixto de $R$. mangle con $L$. racemosa. La estación 3 se ubica de frente al canal principal (Fig. 1), este sitio se encuentra alterado por extracción de madera. La producción promedio mensual de hojarasca obtenida en estos bosques fue de $150,2 \mathrm{~g} / \mathrm{m}^{2}$ (Fig. 2). De esta producción el componente principal corresponde a las hojas de $R$. mangle con el $57,3 \%$. Los valores extremos de la producción de hojarasca se registraron en marzo $\left(82,5 \mathrm{~g} / \mathrm{m}^{2}\right)$ y septiembre $(226,8$ $\left.\mathrm{g} / \mathrm{m}^{2}\right)$, respectivamente. La salinidad y altura de la columna de agua en todos los sitios fueron variables, teniendo un efecto en la producción en todos los bosques (Fig. 2). Los valores extremos para la salinidad fueron de $65 \%$ y de $10 \%$ en febrero y en octubre respectivamente.

Bosques de cuenca: están constituidos por $A$. germinans (estación 4), mientras que en las estaciones 6 y 7 dominan bosques jóvenes de L. racemosa. En el suelo se registró una gran cantidad de sal en la época de secas (65 \%). La producción promedio mensual en estos sitios fue de $92,5 \mathrm{~g} / \mathrm{m}^{2} / \mathrm{mes}$, con un máximo en febrero de $172,5 \mathrm{~g} / \mathrm{m}^{2}$ y un mínimo de $63,2 \mathrm{~g} / \mathrm{m}^{2}$ en julio; el $64,7 \%$ de la producción lo constituyen las hojas de $A$. germinans (Fig. 2). La salinidad intersticial fluctuó entre $65 \%$ y $10 \%$, en mayo y septiembre respectivamente.

Rodal periférico: La estación 8 está constituida por un bosque puro de $C$. erectus, sobre la margen del Río Cahuacán en la periferia de una cuenca. Se registró una producción promedio mensual de $118,3 \mathrm{~g}$ peso $\mathrm{seco} / \mathrm{m}^{2}$, registrándose los valores extremos en abril $\left(83,8 \mathrm{~g} / \mathrm{m}^{2}\right)$ y mayo $\left(154,8 \mathrm{~g} / \mathrm{m}^{2}\right)$ respectivamente; el $73 \%$ del peso está constituido por hojas de C. erectus (Fig. 2). No se registró diferencia significativa entre los tres tipos de bosque. 


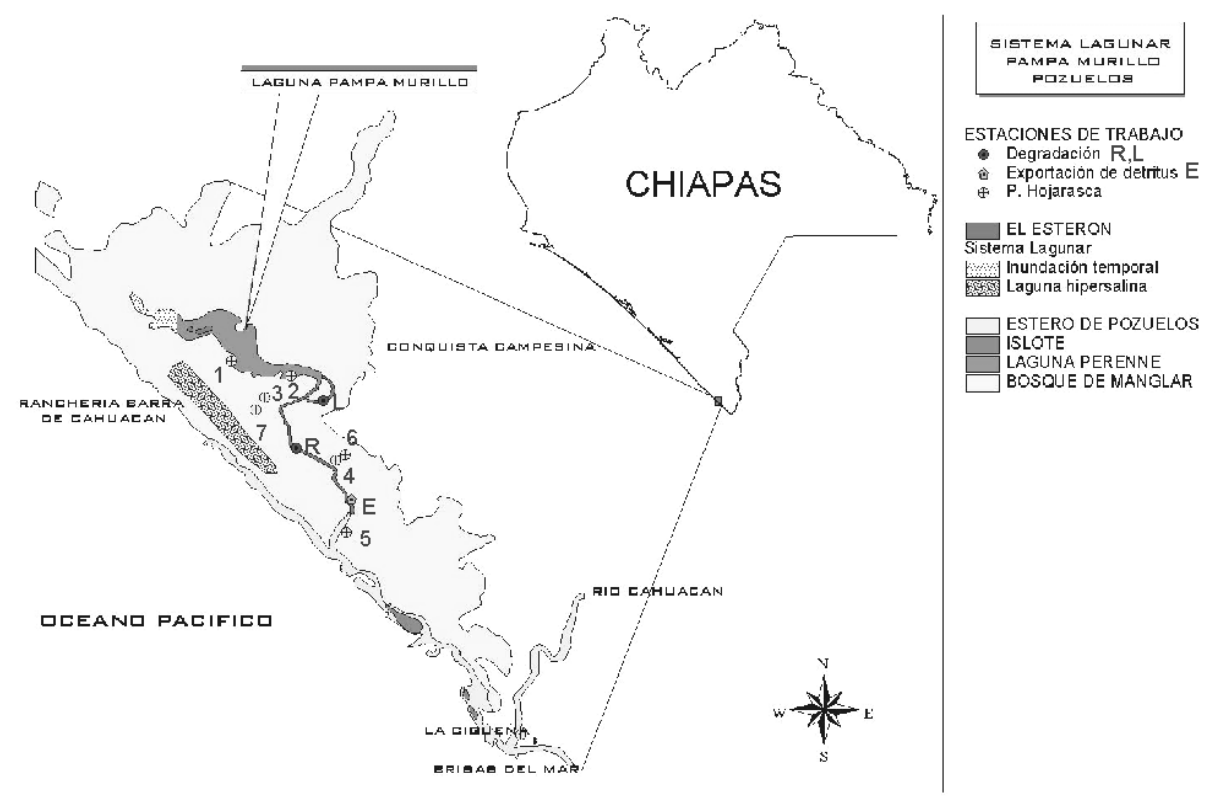

Figura 1. Ubicación del área de estudio.

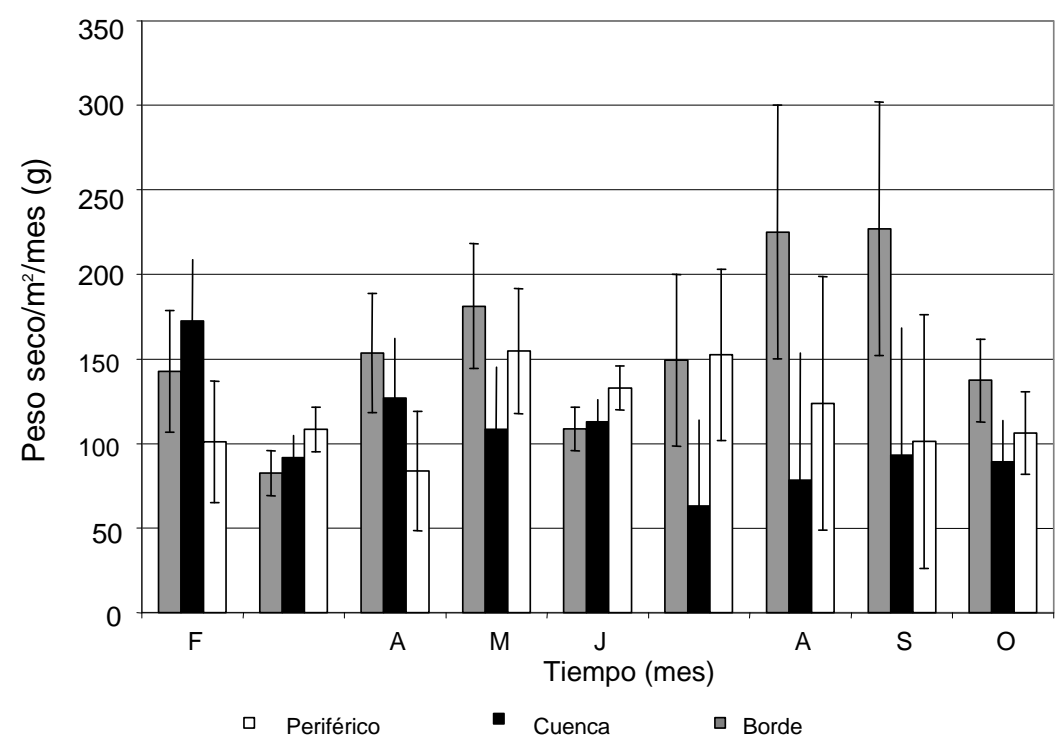

Figura 2. Producción de hojarasca promedio mensual en tres tripos de bosques. 
Herbivoría sobre las hojas: $A$. germinans fue la especie preferida por los herbívoros, con un consumo promedio en peso de $9,7 \%$ para el estrato superior y $17,4 \%$ en el inferior, con un consumo promedio general de $13,5 \%$, este consumo en peso representa el $9,8 \%$ y $17,5 \%$ del área total de las hojas respectivamente, registrándose en octubre y febrero los valores extremos de consumo con $2,1 \%$ y $32,3 \%$, como se observa en la figura 3. Posteriormente, se ubicó el mangle blanco, L. racemosa, con un consumo medio de $9,4 \%$ para las hojas de arriba y $15,3 \%$ para las de abajo (12,4\% promedio), registrándose los extremos de consumo en febrero con $23,6 \%$ y en octubre con $4,0 \%$. En $R$. mangle la proporción de consumo en peso sobre las hojas fue de $5,3 \%$ y 11,2 $\%$ para el estrato superior e inferior respectivamente, con un promedio de 8,2 $\%$. Durante los meses de septiembre $(5,6$ $\%)$ y febrero $(13,2 \%)$ se registraron los valores extremos. La proporción correspondiente en área fue de $8,2 \%$ y $14,5 \%$. Por último, $C$. erectus presentó el porcentaje de consumo más bajo entre las especies estudiadas con $3,3 \%$ y $8 \%(5,7 \%$ de promedio) con los extremos de consumo en marzo (12,6\%) y febrero (2\%), mientras que el área correspondiente en ambos estratos fue de $4,4 \%$ y $8,6 \%$. El mayor consumo sobre las hojas se registró durante la época de secas, con una elevada salinidad intersticial (Fig. 3).

Los herbívoros en $A$. germinans consumieron únicamente el parénquima, dejando el sistema de nervaduras y la cutícula intactos. En $L$. racemosa el consumo fue realizado por organismos mordedores, los cuales consumieron incluso las nervaduras. Las hojas de esta especie, además de los mordiscos, presentaban abundantes perforaciones. También fue notable el grado de suculencia de las hojas en la época de secas.
Para obtener la producción total de hojas de las diferentes especies de mangle, se sumó el promedio obtenido en las trampas y el consumo realizado por los herbivoros. En el caso de $A$. germinans se registraron 10,6 t/ha/año de hojas más $13,5 \%$ de herbivoría $(1,4$ t/ha/año) acumulando un total de 12 t/ha/año. Los valores de consumo por herbivoros para $L$. racemosa fueron de $0,58 \mathrm{t} / \mathrm{ha}$ /año de tejido foliar; mientras que en $R$. mangle y $C$. erectus este consumo se estimó en 0,79 y 0,59 t/ha/año.

Degradación de hojas: se registraron diferencias en la velocidad de degradación en cada una de las especies. El contenido inicial de materia orgánica en las hojas de $A$. germinans fue de $71,3 \%$, el más bajo de las cuatro especies analizadas; durante los siguientes 14 días la materia orgánica (MO) se incrementó hasta $80,0 \%$; este material después de 126 días perdió el $50 \%$ de la MO inicial y al final del experimento, el material restante en las bolsas aún contenía 12,7 $\%$, el total de la pérdida fue de $82,2 \%$ de la cantidad inicial (Fig. 4). En el caso de las hojas de $L$. racemosa se registró un contenido inicial de $\mathrm{MO}$ de $78,5 \%$ y durante los primeros 28 días no se registraron variaciones; después de 140 días las hojas perdieron $50 \%$ de $\mathrm{MO}$, terminando con $14,4 \%$ a los 210 días, acumulando una pérdida total de $81,7 \%$. $R$. mangle fue la especie que presentó la mayor cantidad de $\mathrm{MO}$ en las hojas al inicio, con 87,8\%; después de 140 días perdió más de $50 \%$ de la $\mathrm{MO}$; mientras que a los 210 días aún conservaba 17,7\%, finalizando con una pérdida total de $79,8 \%$.

En las hojas de $C$. erectus, se registró un contenido inicial de $\mathrm{MO}$ de $71,7 \%$; a los 14 días el material incrementó hasta $81 \%$, este enriquecimiento se mantuvo más allá de 56 días. El mangle botoncillo ofreció la mayor resistencia de todas las especies a la degradación. Al finalizar el experimento, las hojas 


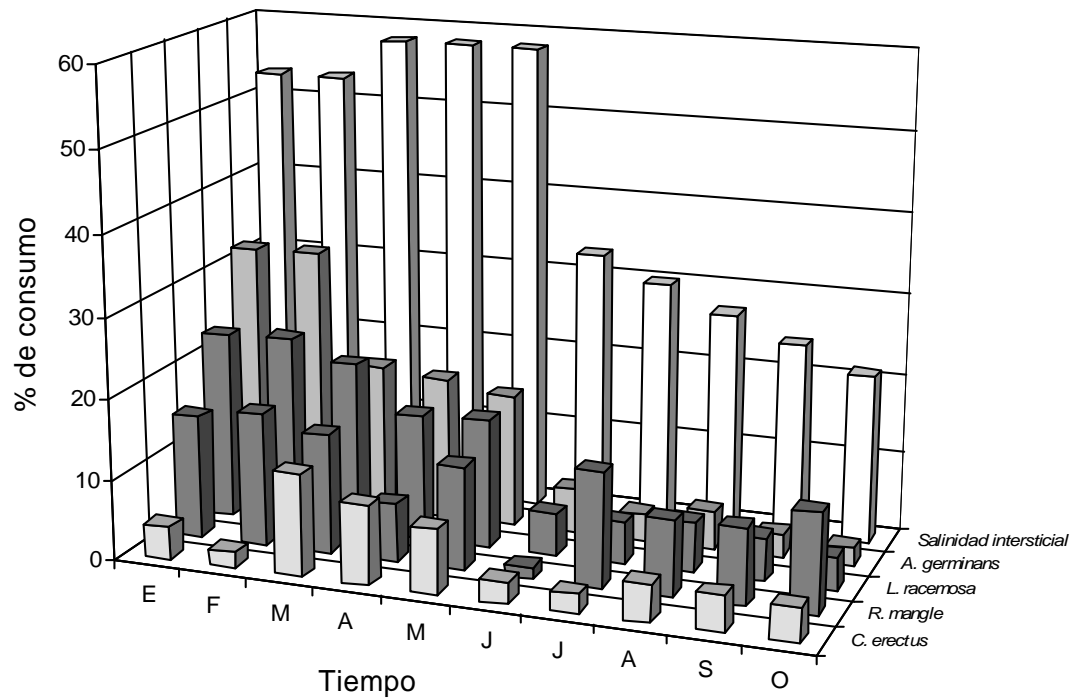

$\square$ C. erectus $\square$ R. mangle $\square$ L. racemosa $\square$ A. germinans $\square$ Salinidad intersticial

Figura 3. Consumo promedio de hojas entre el estrato superior e inferior en las cuatro especies de mangle.

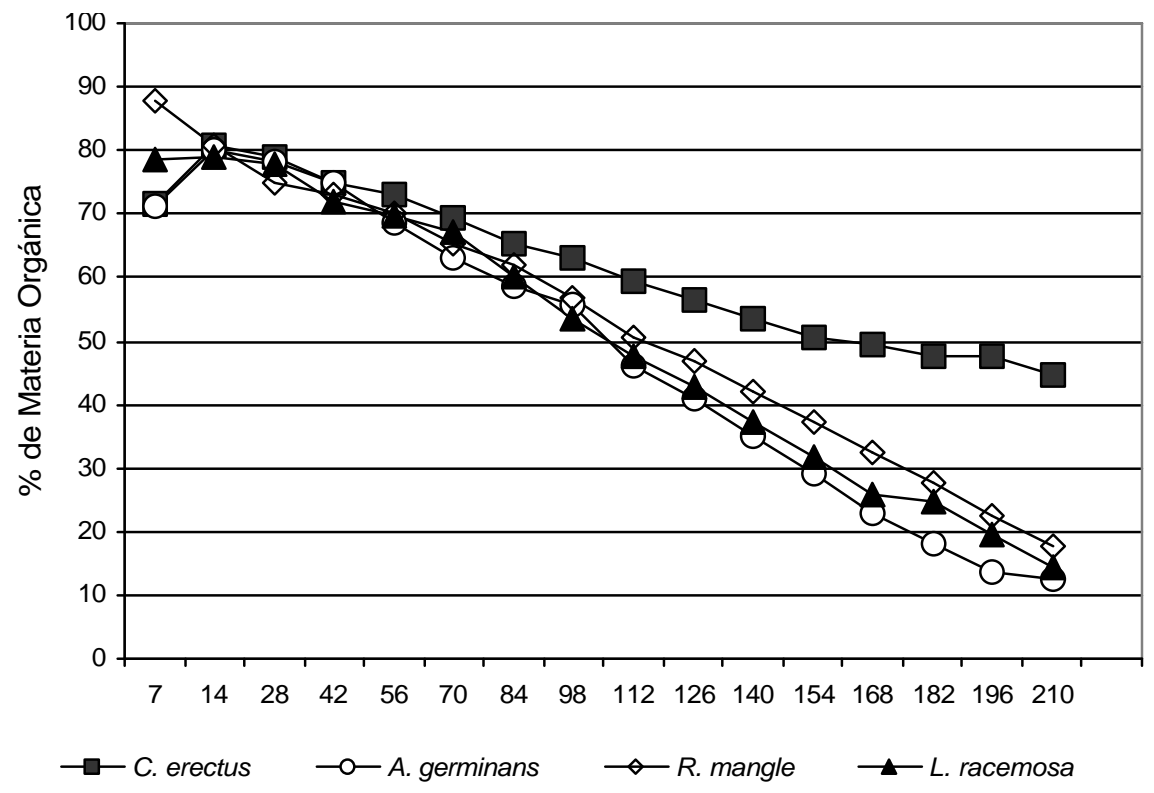

Figura 4. Pérdida de materia orgánica en el tiempo para las cuatro especies de mangle (promedios generales). 
contenían aún 44,7\%, por lo cual se perdió $27 \%$ de la $\mathrm{MO}$ inicial.

Exportación de detritus: el promedio exportado a lo largo del período de estudio por el canal El Esterón es de 59,9 $\mathrm{g}$ de peso seco $/ \mathrm{m}^{3} /$ ciclo de marea; el volumen de agua que pasa por la red en un ciclo de marea es $283117 \mathrm{~m}^{3}$, mientras que a través del canal se exportan $0,9 \mathrm{t}$ de peso seco/h, 21,7 t peso seco/día y 651 t de peso seco/mes, para un total exportado durante el periodo de 6510 toneladas. Los valores más altos se presentaron en octubre con 108,5 g/peso seco/ciclo (1 069,1 t/mes) y los mínimos en mayo con 20,2 g/peso seco/ciclo (352,3 t/peso seco/mes) como se ilustra en la figura 5.
El material exportado durante este periodo presenta una variación en cantidad y calidad. El promedio de $\mathrm{MO}$ contenida en el detritus exportado fue de $54,5 \%$, siendo el máximo en el mes de febrero con $60,8 \%$ y el mínimo en marzo con $45,7 \%$. Se examinaron las fracciones del material colectado por separado: detritus fino ( $\geq 500 \mu \mathrm{y} \leq 1 \mathrm{~mm}$ ) y detritus grueso (partículas $\geq 1 \mathrm{~mm}$ ), se observó que el contenido de $\mathrm{MO}$ en ambas fracciones era variable: la fluctuación de la $\mathrm{MO}$ registrada en el detritus fino varió de $34,7 \%$ a $55,6 \%$ y de $52,5 \%$ a $65,9 \%$ para el grueso. La fluctuación de la temperatura registrada fue de $25^{\circ} \mathrm{C}$ a 28 ${ }^{\circ} \mathrm{C}$, de la salinidad del fondo fue de $30 \%$ 。 a $10 \%$ y la de la salinidad superficial fue de $29 \%-8 \%$ 。

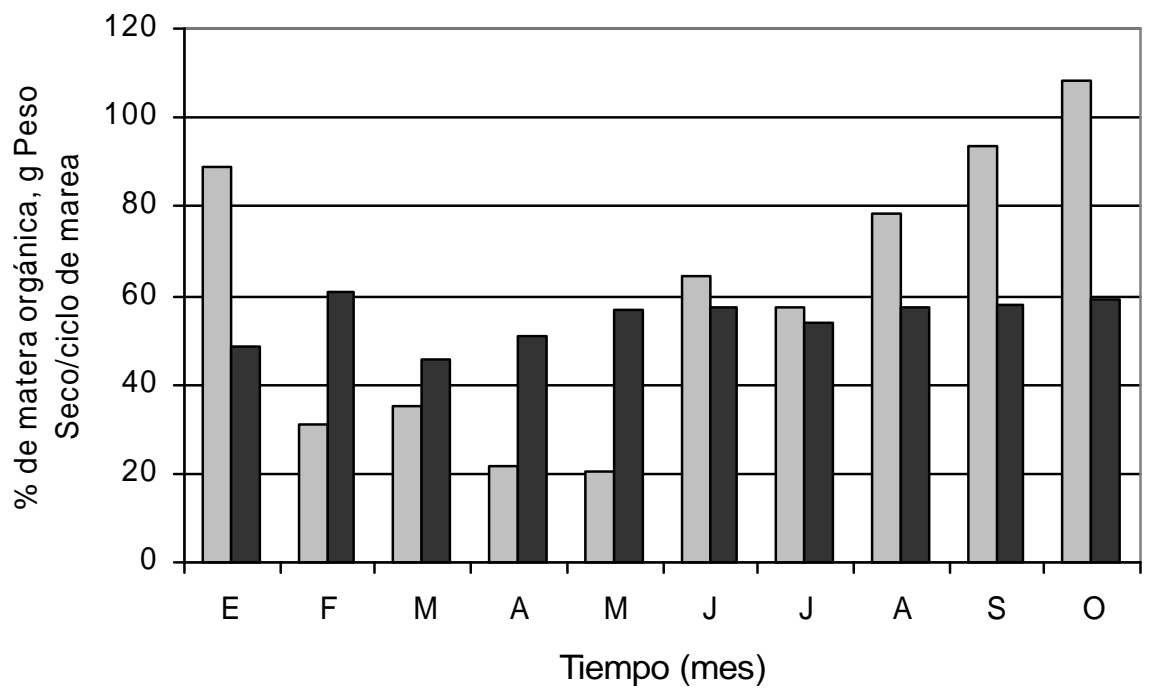

Total (PS)

Prom. MO

Figura 5. Cantidad de detritus exportado hacia la zona marina y calidad nutritiva en \% de materia orgánica. 


\section{DISCUSIÓN}

La producción total de hojarasca aportada por los bosques del Sistema Lagunar Pampa-Murillo, durante los nueve meses de estudio fue de 13,7 t/ha/año, que transformada a carbono equivale a 7,59 t C/año/ha. Estos valores son comparables con los manglares más productivos a nivel ecuatorial (Hernández y Mullen, 1979; Cintrón et al., 1978; Sasekumar y Loi, 1983).

En los bosques de borde, la mayor producción es aportada por $R$. mangle en condiciones de suelo inundado y salinidades menores a $12 \%$; mientras que en las cuencas la mayor producción corresponde a $A$. germinans, especie que requiere menor cantidad de agua en el suelo y salinidades mayores a $15 \%$, estas condiciones también han sido registradas en otras localidades, aún más, la producción en los rodales de borde de este sistema es mayor a la registrada en otras localidades ecuatoriales con mayores precipitaciones (Pannier, 1959; Lugo et al., 1980; Tovilla, 1998). Los sitios más productivos se localizaron a lo largo de canales de marea donde se garantiza una dilución permanente y un aporte de nutrientes y sedimentos continuos durante el año; estos sitios están dominados por bosques monoespecíficos de R. mangle (Lugo y Snedaker, 1974; Odum y Heald, 1975).

La producción obtenida en los bosques de cuenca fue del orden de 4,2 $\mathrm{g} / \mathrm{m}^{2} / d i ́ a$, esta producción es superior a los valores encontrados en otras localidades ubicadas a la misma latitud en el Golfo de México y en el Pacífico (Tovilla y González, 1994; Jardiel et al., 1987; López-Portillo y Ezcurra, 1985). Probablemente, la elevada producción en estos sitios es consecuencia de un reciclamiento rápido de la materia orgánica debido a la degradación de la hojarasca de $A$. germinans que en 210 días pierde $82,2 \%$ de MO.

La producción en estos rodales está relacionada con la duración del ciclo de vida de las hojas. El incremento en la cantidad de agua dulce y nutrientes en una temporada, provoca un incremento en la producción de hojarasca durante el año siguiente. Otro factor que probablemente aumenta la producción de hojarasca es la incidencia de tormentas tropicales, como sucedió durante los meses de agosto y septiembre con el paso de la tormenta Chantal, las cuales favorecieron la defoliación y la sustitución acelerada por hojas nuevas en el área de estudio, esto también se ha observado en el Mar Caribe (Boucher, 1990; Imbert et al., 1996; McCoy et al., 1996).

Herbivoría sobre hojas de mangle: la herbivoría es parte del ciclo de vida de las plantas y los manglares no se encuentran excentos de ella. Este fenómeno estimula el desarrollo, recambio foliar, floración y fructificación en los manglares (Simberloff et al., 1978; Stilling, 1999, Krebs, 2001). La cuantificación de la producción de hojarasca y la estimación de la pérdida de tejido foliar son estimadores para calcular el porcentaje de la producción de hojarasca que se desvía dentro del sistema, tomando como base el consumo realizado por los herbívoros. La estimación del consumo realizado por los organismos sobre las hojas de las cuatro especies de mangles en Pampa Murillo se puede clasificar de acuerdo con la escala de Robertson y Duke (1987) como un consumo medio-alto en $A$. germinans $(13,6 \%)$ y L. racemosa (12,5\%); mediobajo en R. mangle $(9,8 \%)$ y bajo en $C$. erectus $(5,7 \%)$. Valores ligeramente menores fueron estimados por Tovilla (1998) en A. germinans, L. racemosa, C. erectus y $R$. mangle en un manglar de las costas del estado de Guerrero en el Pacífico sur de México, mientras que 
tasas de consumo muy bajas sobre $R$. mangle y $A$. germinans fueron calculadas por Onuf et al. (1977) en Florida. Por el contrario, en Belice, Farnsworth y Ellison (1991) registraron que hasta un $88 \%$ de las hojas de $R$. mangle presentaban indicios de pastoreo, sin hacer una estimación fina de este consumo.

Existen diversas hipótesis formuladas para definir las causas que provocan un mayor o menor pastoreo sobre las hojas de los manglares como: el grado de exposición al sol y a la sombra, la altura del dosel (Johnstone, 1981; Robertson y Duke, 1987), la edad de los árboles y el grado de enriquecimiento del suelo en donde prosperan (Robertson y Duke, 1987; Farnsworth y Ellison, 1991). El factor más importante en la tasa de consumo por herbivoros es el contenido de algunas sustancias como taninos solubles así como una elevada proporción de C:N, las cuales actúan como defensas foliares dificultando la palatabilidad y/o la digestibilidad de las hojas (White, 1978; Lowman y Box, 1983; Giddins, 1984). Sin embargo, en este estudio se encontró una relación directa entre la tasa de degradación de las hojas de $A$. germinans y la herbivoría. Especies con tasas de degradación bajas son menos consumidas por herbivoros (e.g. C. erectus). Esto indica que también puede haber factores físicos que influyen en la palatabilidad.

En este trabajo se observó la presencia de diferentes consumidores en $A$. germinans y $R$. mangle. Mientras que $R$. mangle comparte defoliadores con $L$. racemosa, no lo hace con $A$. germinans. Esta diferencia es explicada por el contenido de lípidos, esteroles y terpenos en las hojas entre la familia Aviceniaceae y Rhizophoraceae (Farnsworth y Ellison, 1991; Ghosh et al., 1985). Se encontró también que los lepidópteros son los organismos más frecuentes y abundantes sobre las cuatro especies de mangles en su fase de orugas, principalmente en $A$. germinans, $R$. mangle y $L$. racemosa.

Los manglares, aún cuando presentan defensas formidables ante el ataque de algunos organismos, pueden ser afectados drásticamente por otros, al variar algunos de los parámetros ambientales como la salinidad y el nivel de inundación. El aumento en herbivoría en Pampa Murillo coincide con un aumento de la salinidad y la temperatura en época de secas; por el contrario, durante los meses más lluviosos (junio, julio), este fenómeno disminuye notablemente. Los extremos en salinidad del suelo aparentemente favorecen el forrajeo, probablemente porque las plantas son más vulnerables al ataque de los herbívoros cuando uno o varios factores ambientales modifican el estado fisiológico de la planta (Johnstone, 1981; Robertson y Duke, 1987).

Degradación de hojas: Depende en gran parte de la situación del suelo cuando caen las hojas; si el manglar está inundado, la degradación es rápida, de lo contrario se degrada más lentamente. Los procesos que probablemente aceleran la degradación son el arrastre por las mareas y la llegada de la época de lluvias, desencadenando rápidamente el proceso de degradación in situ. El efecto de la marea sobre la degradación depende del tipo de bosque de manglar.

El contenido de taninos que puede inhibir la acción de los microorganismos y la cantidad de compuestos nitrogenados en las hojas son factores que modifican el tiempo de descomposición de la MO, como ha sido demostrado por Cundell et al. (1979). En este proceso, el material vegetal, inicialmente bajo en proteínas, es transformado en partículas más pequeñas de detritus pero con cantidades mayores de proteínas de origen microbiano; los almidones y azúcares se oxidan al mismo tiempo que sucede un 
incremento de las proteínas, debido a la colonización de la superficie del detritus por bacterias y hongos, provocando que poblaciones de ciliados y nemátodos pastoreen, ingiriendo las partículas más pequeñas; estos a su vez, son consumidos junto con partículas más grandes por organismos detritófagos como anfípodos, gasterópodos, bivalvos y poliquetos (Fenchel, 1970; Cundell et al. (1979). Al pasar por el tracto digestivo de estos organismos, el núcleo vegetal no sufre gran alteración, pero puede ser nuevamente fragmentado; las fracciones no digeridas son defecadas y nuevamente colonizadas, hasta que la materia orgánica es totalmente aprovechada. Por esta razón, el material foliar como fuente de alimento aumenta su calidad nutricional durante la degradación.

C. erectus es importante por su aporte de hojarasca al sistema, desafortunadamente las áreas cubiertas por esta especie son mínimas, además de que su elevada concentración de celulosa y lignina retrasan el proceso de degradación, además, sus hojas se depositan sobre suelos arenosos y con poca humedad, en estos ambientes, la desintegración es más tardada. $R$. mangle contiene porcentajes importantes de N, P y materia orgánica. Sin embargo, es muy resistente a la descomposición debido a un elevado contenido de celulosa y taninos, a pesar de ello un factor favorable para este proceso es que las hojas caen al agua, donde la velocidad de degradación es mayor. L. racemosa es pobre en ambos compuestos, pero las hojas se degradan rápidamente y de la misma manera que el mangle rojo cae en el agua (Tovilla, 1998).

Las diferencias en la velocidad de degradación observadas sugieren que la acción mecánica de la corriente propicia la fragmentación del material, acelerando el proceso de descomposición, otro factor que contribuye también es la presencia de gran cantidad de cangrejos, isópodos y algunos poliquetos, los cuales contribuyen al proceso de degradación.

La degradación inicia con la autólisis (proceso que sucede más rápido cuando la salinidad y la temperatura son elevadas, como se observó en el canal donde se colocaron a degradar las hojas, $27 \%$ a $0 \%$ y $35^{\circ} \mathrm{C}$ a $27^{\circ} \mathrm{C}$, y cuando el material es depositado en el agua hundiéndose inmediatamente); en este proceso no intervienen los microorganismos. La pérdida de MO durante la autólisis logra ser recuperada parcialmente mediante el incremento bacteriano, aumentando aproximadamente un $10 \%$ del contenido inicial (Fig. 4, A. germinans y $C$. erectus). Posteriormente sucede la lixiviación y mineralización, procesos altamente dependientes de las bacterias y hongos que abundan dentro de estos ambientes. En los primeros 14 días se pierde entre $80 \%$ y $100 \%$ de la materia orgánica soluble y el carbono contenido en las hojas, como ha sido demostrado por Fell y Master (1974) y Camilleri y Ribbi (1983).

Exportación de detritus hacia la zona marina: los ecosistemas de manglar exportan, a lo largo del año, diferentes cantidades de detritus con diferente calidad hacia la zona marina. Los manglares de zonas cercanas al ecuador registran los mayores aportes, probablemente por haber mayor precipitación y aportes de agua dulce más voluminosos (Golley, 1983; Boto y Robertson, 1990; Robertson et al., 1992; Wolanski, 1995). Esta exportación depende de los mecanismos de remoción de detritos, de la cobertura del bosque, del nivel de inundación, de la altura de la marea, de la producción de hojarasca y de la velocidad de degradación. Robertson et al. (1992) en un manglar de Australia, observaron que en los bosques inundados, sólo un 20 $\%$ de la materia orgánica se degradaba, mientras que el resto era exportado hacia 
la zona marina. Por el contrario, en el sistema Lagunar Pampa Murillo, más de $50 \%$ del material se degradó en los primeros 113 días, en ese momento cada gramo de detritus exportado contenía en promedio $54,5 \%$ de MO. Con este contenido de $\mathrm{MO}$, el detritus presenta una gran colonización bacteriana, lo cual incrementa su calidad nutritiva (la fragmentación del material ofrece mayor superficie de colonización). La calidad del detritus está en función del tiempo y de los mecanismos de fragmentación y de movimiento del material anteriormente citado; por ejemplo Robertson et al. (1992) en un manglar de Australia, observaron que 72 $\%$ del material depositado en las cuencas era removido entre 10 y 18 días posteriores a su depositación, conteniendo 67 $\%$ de $\mathrm{MO}$ en su estructura; por el contrario Day et al. (1996) en Laguna de Términos, México, estimaron que el tiempo de remoción de detritus dentro de las cuencas y los bosques de borde se realiza en un término de 200 a 300 días. En Pampa Murillo durante la máxima lluvia de agosto, septiembre y octubre, el nivel de agua en los manglares forma un nivel de inundación continuo, logrando una gran redistribución del detritus, aún aquel que se encuentra en las cuencas, como se observó en estos meses, durante los cuales se registró un aumento sustancial de la cantidad de detritus y hojarasca en el agua de El Esterón flotando hacia el estuario y las aguas costeras adyacentes. Los valores elevados de detritus durante los últimos meses se debieron adicionalmente al significativo aporte de agua dulce por los ríos que subsidian el humedal. Robertson et al. (1992) mencionan que en algunos sitios del sureste asiático se registra una exportación de materia orgánica de 10 t/ha/año a 14 t/ha/año (Fig. 6) proveniente de los manglares; de esta cantidad, al menos $10 \%$ es transformada en biomasa animal, que van desde estadios larvarios hasta ejemplares adultos de peces, moluscos y crustáceos entre otros, que se alimentan de materia orgánica proveniente del manglar; muchos de ellos residentes permanentes en los estuarios, mientras otros únicamente lo utilizan en una parte de su ciclo vital. Muchas de las grandes pesquerías comerciales del Pacífico sur de México como el camarón, dependen de estos subsidios, p.e. frente a la desembocadura del Río Cahoacán; donde desemboca El Esterón existe una de las mejores áreas de pesca de camarón y pesca de mersal de la costa de Chiapas.

\section{CONCLUSIONES}

Con los resultados de esta investigación se obtuvieron las piezas principales para construir un modelo de flujo de materia. El Sistema Lagunar de PampaMurillo funciona como un todo, a partir de los subsidios de materia (nutrientes, sedimentos, agua dulce, salobre y materia orgánica) y energía (luz, temperatura, oleaje, vientos, marea y huracanes) que recibe. Estos subsidios permiten que los bosques de manglar produzcan una cierta cantidad de materia orgánica, la cual está distribuida de la siguiente forma: los bosques de borde producen en promedio 10,4 t C/ha/año, cantidades menores se registraron en el bosque de $C$. erectus con 3,9 tC/ha/año ó 7,9 t C/ha/año; mientras que las cuencas registraron los valores más bajos con 3,1 t $\mathrm{C} / \mathrm{ha}$ /año ó 6,9 t C/ha/año, representando el flujo de materia dentro de este sistema.

Sobre la producción de hojarasca, los herbívoros ejercen un consumo directo, el cual varía de acuerdo con la preferencia de los organismos sobre cada especie: siendo $A$. germinans la que soporta la tasa de forrajeo más intensa con 0,79 t C/ha/año, seguido por $R$. mangle, $C$ erectus y $L$. racemosa con 0,44 t C/ha/año, 0,33 t C/ha/año y 0,32 t $\mathrm{C} / \mathrm{ha} / \mathrm{año}$, respectivamente; el total del 


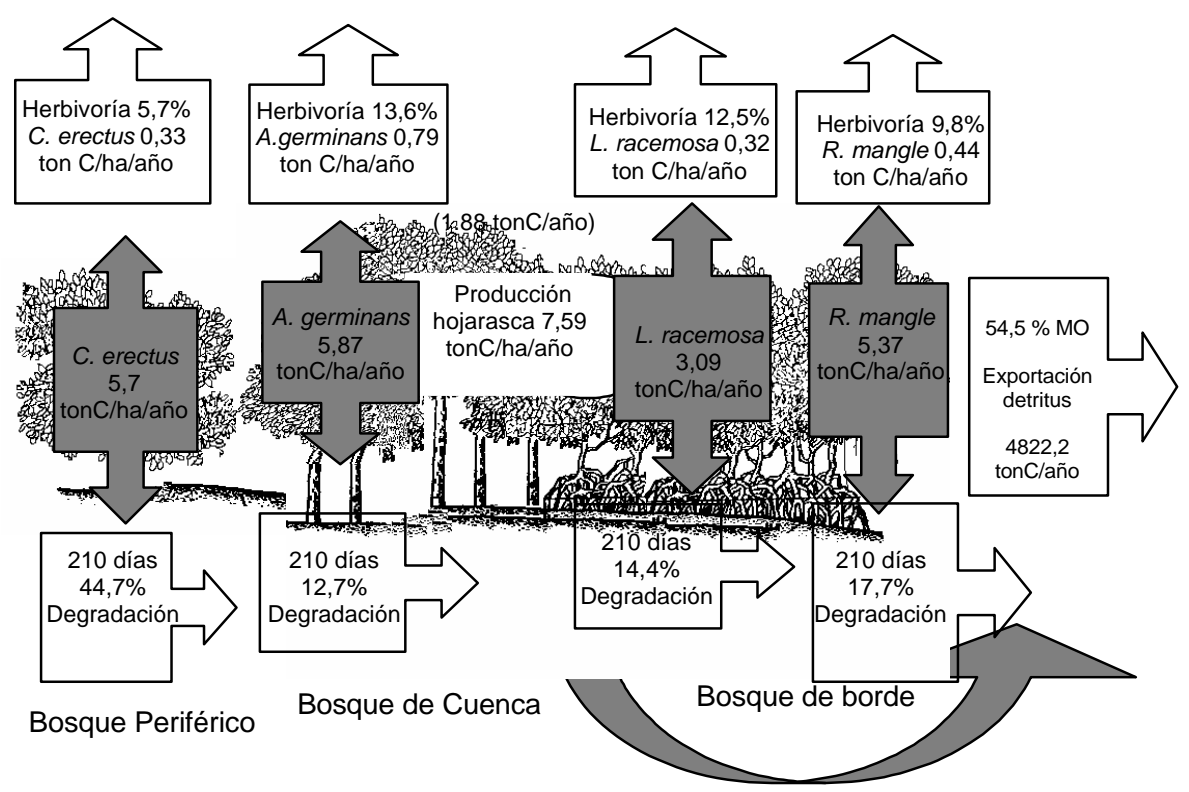

Figura 6. Modelo de flujo de materia en el Sistema Lagunar Pampa Murillo.

consumo realizado por los organismos equivale a $1,88 \mathrm{t} \mathrm{C} / \mathrm{ha} / \mathrm{año}$, cantidad que debe adicionarse a la producción de hojarasca del sistema, para un total de $9,47 \mathrm{t}$ C/ha/año.

La hojarasca aportada por las cuatro especies de mangle registra diferente resistencia a la degradación. Puede ser tan lento como 210 días en $C$. erectus, cuando se logra degradar menos de $50 \%$ del material o tan rápido como un lapso de 196 días para A. germinans. Buena parte de este material es removido constantemente por las corrientes de marea. A los 113 días el detritus exportado aún contenía $54,4 \%$ de MO, una calidad aceptable que puede tolerar un forrajeo intenso por diferentes organismos en la zona marina por otro periodo semejante. Finalmente, este sistema envía a la zona marina un subsidio de materia equivalente a 4 822,2 tC/ha/año. La exportación de detritus está acompañada de la exportación de materia orgánica disuelta, la cual es un subsidio a los sistemas costeros no cuantificado.

\section{RECONOCIMIENTOS}

Los autores agradecen el apoyo financiero brindado por ECOSUR Tapachula y al Laboratorio de Ecología de Manglares Unidad Tapachula para la realización del trabajo. A Jesús Carmona de la Torre y a Juan Jesús Morales López del Laboratorio de ECOSUR Unidad San Cristóbal de las Casas por el apoyo brindado para el uso del medidor de área foliar. A los pescadores del Sistema Lagunar Pampa Murillo Ricardo y Otho; Patricia Velazco, Giselle Flores y Miguel A. Chargoy quienes participaron en el trabajo de campo. Finalmente a Diana L. R. O. por el apoyo brindado. 


\section{REFERENCIAS}

Baldor, A.T. 1981. Geometría. 22 edición. Ed. Publicaciones Culturales S. A. México. 344 p.

Beever, J.W. III; D. Simberloff y L. King. 1979. Herbivory and predation by the mangrove tree crab Aratus pisonii. Oecologia 43:317-28.

Boto, K. G. y A.I. Robertson. 1990. The relationship between nitrogen fixation and tidal exports of nitrogen in a tropical mangrove system. Estuarine Coastal and Shelf Science 31:531540.

Boucher, D.H. 1990. Growing back after hurricanes. BioScience. 40(3):65-72

Bremer, G.B. 1995. Lower marine fungi (Labyrinthulomycetes) and the decay of mangrove leaf litter. Hydrobiologia 295(1-3): 89-96.

Brown, S. y A.E. Lugo. 1981. The storage and production of organis matter in tropical forests and there is. The Global Carbone cycle. Biotropica 14(3):161-187.

Camilleri J., C. y G. Ribbi. 1983. Leaf thickness of mangroves (Rhizophora mangle) growing in different salinities. Biotropica 15(2):139-141.

Cintrón G.; M.; C. Goenaga y J. GonzálezLiboy. 1978. Ecología del manglar en una costa árida: exposición al oleaje y estructura del manglar. Memorias del V Simposio Latinoamericano sobre Oceanografía Biológica. Sao Paulo, Brasil. 34-42

Cintron, G. y Y. Shaeffer-Novelli. 1981. Roteiro para estudio dos recursos de marismas e manguezais. Int. Oceanog. Sao Paulo 10:1-13.
Cundell, A.M.; M.S. Brown; R. Stanford y R. Mitchell. 1979. Microbial degradation of Rhizophora mangle leaves inmersed in the sea. Estuarine and Coastal Mar. Sci. 9:281-286.

Day Jr., J.W.; C. Coronado-Molina; F.R. Vera-Herrera; R.R. Twilley; V.H. Rivera-Monroy; H. Alvarez-Guillen; R. Day y W. Conner. 1996. A 7 year record of above-ground net primary production in a southeastern Mexican mangrove forest. Aquatic Botany 55:39-60.

Farnsworth, E.J. y A.M. Ellison. 1991. Patterns of herbivory in Belizean mangrove swamps. Biotropica 23(4b):555-567.

Fell, J.W. e I.M. Master. 1974. Fungi associated with the degradation of mangrove $R$. mangle, leaves in south Florida. In: H.L. Stevenson y R.R. Colwell (Eds.). Estuarine microbial ecology. University of South Carolina Press. Columbia. 455-466.

Fenchel, T. 1970. Studies on the decomposition of organic detritus derive from turtle grass Thalassia testudinum. Limnol. Oceanogr. 15(1):14-20.

Flores-Verdugo, F.; J. Day y R. BriseñoDueñas. 1987. Structure, litter fall, decomposition, and detritus dynamics of mangroves in a Mexican coastal lagoon with an ephemeral inlet. Marine Ecology Progress Series 35:83-90.

Ghosh A.; S. Misra; A. K. Dutta y A. Choudhury. 1985. Pentacyclic triterpinoids and sterols from seven species of mangrove. Phytochemistry 24:1725-1727.

Giddins R. 1984. The use of the litter of the mangrove Ceriops tagal as food 
by the tropical sesarmid crab Neosarmatium smithii. BSc. (Horns) Thesis. James Cook University of North Queensland. 135 p.

Golley, F.B. 1983. Tropical ecology whith emphasis on organic productivity. In: F.B. Golley y R. Mirsa (eds) Tropical Ecology. Univ. of Georgia, Athens. 402-413.

Golley, F.B.; H.T. Odum y R. F. Wilson. 1962. The structure and metabolism of a Puerto Rican red mangrove forest in May. Bull. Marine Sci. 1:34-62.

Heald, E.J. 1969. The production of organic detritus in a South Florida estuary. Univ. Miami. Sea Grant Tech. Bull. 6. 110 p.

Hernández, A. y K. Mullen. 1979. Productividad primaria neta en un manglar del Pacifco Colombiano. Memorias del Simposium sobre Pacífico Colombiano. Universidad del Valle. Cali, Colombia. 120 p.

Imbert, D.; P. Labbe y A. Rousteau. 1996. Hurricane damage and forest structure in Guadaloupe, French West Indies. Journal of Tropical Ecology 12:663-680.

Jardiel, J.E.; A.A. Saldaña y M. T. Barreiro. 1987. Contribución al conocimiento de la ecología de los manglares de la laguna de Términos, Campeche, México. Ciencias Marinas 17:24-35.

Johnstone, I. M. 1981. Consumption of leaves by herbivores in mixed mangrove stands. Biotropica 13.pp 252-9.

Krebs, C.J. 2001. Ecology. Benjamin Cummings. 5a. ed. San Francisco. $698 \mathrm{pp}$.
Lacerda, G.D.; J.E. Conde; C.Alarcón; R. Alvarez-León; P.R. Bacon; L. D’Croz; B. Kjertve; J. Polonía y M. Vannucci. 1993. Ecosistemas de manglar de América Latina y el Caribe: Sinopsis. In: Conservación y aprovechamiento sostenible de bosques de manglar en las regiones América Latina y Africa. Ecosistemas de manglares informes técnicos. Vol. 2. Proyecto ITTO/ISME PD114/90 (F). Coor-dinador del Proyecto: G. D. Lacerda. Noviembre. p:1-38.

Lee, S.Y. 1995. Mangrove outwelling: a review. Hydrobiologia 295(1-3):203212.

López-Portillo, J. y E. Ezcurra. 1985. Litterfall of Avicennia germinans in a one-year cycle in a mudflat at the Laguna de Mecoacan, Tabasco, México. Biotropica 17 (3):186-190.

Lowman, M.D. y J.D. Box. 1983. Variation in leaf toughness phenolic content among five species. Properties of a mangrove forest in southern Florida. In: G. Walsh, S. Snedaker y H.Teas (eds). Proceedings of the international symposium on the biology and management of mangroves. Univ. of Florida Gainesville. 170-211.

Lugo, A. y S. Snedaker. 1974. The ecology of mangroves. Annu. Rev. Ecol. Sist. 5:39-64.

Lugo A.; G. Cintrón y C. Goenaga. 1980. El ecosistema de manglar bajo tensión. In: Memorias del Seminario sobre estudio científico e impacto humano en el ecosistema de manglares. UNESCO. Montevideo. p:261-285.

Lugo, A.E.; S. Brown y M.M. Brinson. 1990. Concepts in wetland ecology. In: Lugo, A.E., M.M. Brinson y S. 
Brown (eds): Forests Wetlands: Ecosystems of the World 15. Elsevier. Holanda. 53-79.

McCoy, E.D.; H.R. Mushinsky; D. Johnson y W.E. Meshaka Jr. 1996. Mangrove damage caused by hurricane Andrew on the southwestern coast of Florida. Bulletin of Marine Science 59(1):1-8.

Odum, W.E. y E.J. Heald. 1975. The detritus-based food web of an estuarine mangroves community. In: Cronin, L.E. Estuarines Research (Ed.). Academic Press. Nueva York. p: 265-286.

Onuf, C.P.; J.M. Teal e I. Valiela. 1977. Interactions of nutrients, plant growth and herbivory in a mangrove ecosystem. Ecology 58:514-526.

Pannier, F.P. 1959. El efecto de distintas concentraciones salinas sobre el desarrollo de Rhizophora mangle L. Acta Científica Venezolana, Botánica 10:68-78.

Rico-Gray, V. y A. Lot-Helgueras. 1983. Producción de hojarasca del manglar de la Laguna de la Mancha. Biótica 8(3):295-301.

Robertson, A.I. y N.C. Duke. 1987. Insect herbivory on mangrove leaves in North Queensland. Australian Journal of Ecology 12:1-7.

Robertson, A.I.; D.M. Alongi y K.G. Boto. 1992. Food chains and carbon fluxes. In: Robertson, A.I. y D.M. Alongi (eds). Coastal and estuarine studies 41: Tropical Mangrove Ecosystems. American Geophysical Union. Washington, D. C. p:293-326.

Sasekumar, A. y J.J. Loi. 1983. Litter production in three mangrove forest zones in the Malay Penninsular. Acuatic Botany 17:283-290.

SERNyP. 1998. Estudio técnico justificativo de los humedales Pampa Murillo para proponerlos como Área Natural Protegida. Dirección de Ecología y Protección Ambiental. Gob. del Estado de Chiapas. 80 p.

Simberloff, D.S.; B.J. Brown y S. Lowrie. 1978. Isopod and insect rood borers may benefit Florida mangroves. Science 201:630-632.

Southwell, C.R. y J.D. Boltman. 1971. Marine borer resistances of untreated woods over long perids of inmersion in tropical waters. Biotropica 3:81-107.

Steinkey, T.D. y L.M. Charles. 1983. Degradation of mangrove leaf and stem tissues in situ in Mgeni Estuary, South Africa. 141-150. In: Teas, H.J. (Ed.). Biology and ecology of mangroves. Dr. W. Junk Publishers. 25-36.

Steinkey, T.D. y L.M. Charles. 1984. Productivity and phenology of Avicennia marina (Forsk.) Vierh. and Bruguiera gymnorhiza (L.) Lam. in Mgeni Estuary, South Africa. In: Teas, H.J. (Ed.) Physiology and Management of Mangroves. Dr. W. Junk Publishers. 22-31.

Stilling, P. 1999. Ecology, theories and application. Third edition. Ed. Prentice-Hall, Inc. EUA. p: 292-314 y 390-393.

Tovilla H., C. 1998. Ecología de los bosques de manglar y algunos aspectos socioeconómicos de la zona costera de Barra de Tecoanapa, Guerrero, México. Tesis Doctoral Facultad de Ciencias. UNAM. México. 395 p. 
Tovilla H., C. y A.E. González. 1994. Producción de hojarasca del manglar en tres sistemas lagunares del Golfo de México y el Pacífico. In: Grandes Temas de la Hidrobiología: Los Sistemas Litorales.UAMI-UNAM 2:87-103.

Ulken, A. 1984. The fungi of the mangal ecosystem. In: Dov, P.F. e I. Dor (eds) Hydrobiology of the Mangal.
Dr. W. Junk Publishers. The Hague. 27-34.

White, T.C.R. 1978. The importance of a relative shortage of food in animal ecology. Oecologia 33:71-86.

Wolanski, E.1995. Transport of sediment in mangrove swamps. Hidrobiologia 295(1-3):31-42.»

Manuscrito recibido el 24 de agosto de 2003.

Aceptado el 2 de abril de 2004.

Este documento se debe citar como:

Orihuela B., D.E.; C. Tovilla H.; H.F.M. Vester y T. Álvarez L. 2004. Flujo de materia en un manglar de la costa de Chiapas, México. Madera y Bosques Número especial 2:45-61. 